\title{
As bombas atômicas podem dizimar a humanidade - Hiroshima e Nagasaki, há 70 anos
} EMICO OKUNO $^{1}$

$\mathrm{P}$ ARA QUE NUNCA mais se repita a hecatombe nuclear repleta de destruição, devastação, terror, dor e tristeza, é preciso rememorar o que aconteceu no Japão há 70 anos!

Às 8h15 do dia 6 de agosto de 1945, os americanos jogaram o "Little Boy", uma bomba atômica, na cidade de Hiroshima, devastando-a. Como era segunda-feira, a essa hora, os estudantes já estavam em salas de aula e os empregados em seus locais de trabalho. O bombardeiro americano B-29, transportando a bomba atômica, Little Boy, pilotado pelo coronel Paul Warfield Tibbets Jr. havia decolado da Ilha Tinian às 2 h45 e chegou a Iwojima às 5 h 52 , de onde seguiu para Hiroshima. Na véspera, Tibbets havia pintado na fuselagem da aeronave o nome de sua mãe, Enola Gay. Duas outras aeronaves B-29, The Great Artist, carregando vários instrumentos de medida, e o Necessary Evil, com equipamentos fotográficos para registro, escoltaram o Enola Gay. A cidade de Hiroshima havia sido eleita para bombardeio porque, diferentemente de outras cidades de dimensão similar, Hiroshima estava razoavelmente intacta e os efeitos de uma bomba atômica seriam “espetaculares” para mostrar ao mundo o poderio americano, detentor da devastadora arma de destruição em massa.

Três dias depois foi a vez de Nagasaki. Às 3h49 do dia 9 de agosto de 1945 o B-29 Bock's Car pilotado pelo major Charles W. Sweeney decolou de Tinian para bombardear visualmente a imensa fábrica de armamentos em Kokura, mas por falta de visibilidade o alvo foi mudado para Nagasaki onde a bomba atômica "Fat Man” explodiu às 11h02. The Great Artist que escoltou o Bock's Car deixou cair antes da bomba uma lata com uma carta sem assinatura dirigida ao professor Ryokichi Sagane, físico nuclear da Universidade de Tóquio, que havia realizado pesquisas em Berkeley na Universidade de Califórnia com três dos cientistas responsáveis pela construção de bombas atômicas. A carta manuscrita, cuja cópia é mostrada na Figura 1, continha a mensagem de que o público japonês fosse informado dos perigos dessa arma de destruição em massa. A carta foi encontrada por autoridades militares japonesas que só a entregaram ao professor Sagane um mês depois. Em 22 de dezembro de 1949, um dos autores da carta, Luis Walter Alvarez, encontrou Sagane e assinou o documento.

Naquela época, Tinian, uma das três ilhas do arquipélago das Ilhas Maria- 
nas, era um local altamente estratégico para lançar ataques diretos ao Japão do qual dista apenas cerca de $2.400 \mathrm{~km}$. Os americanos construíram ali a maior e mais movimentada base aérea durante a Segunda Guerra Mundial.

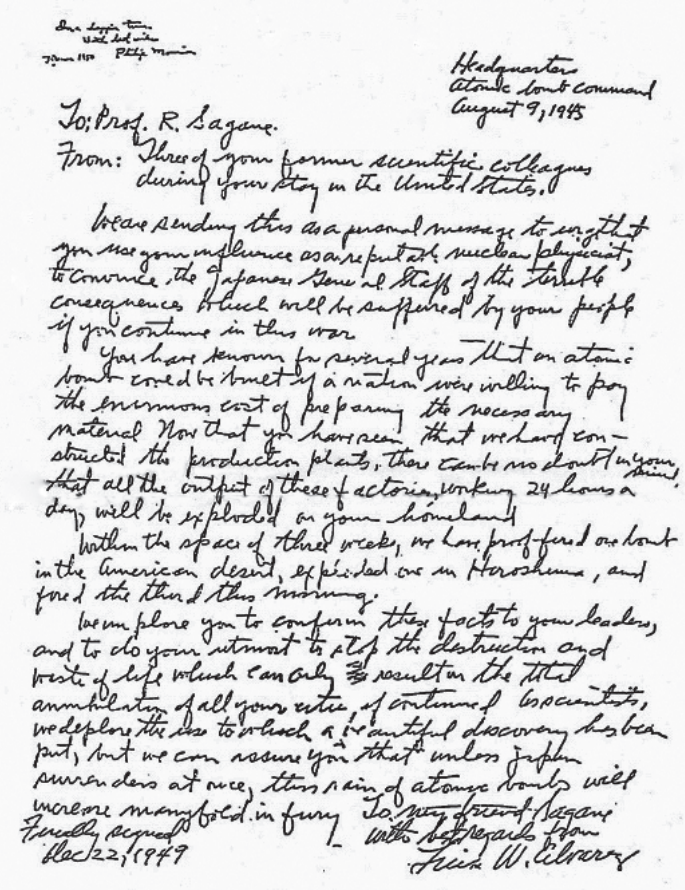

Fonte: Disponível em: <http://www.lettersofnote.com/2009/12/this-rain-of-atomic-bombs-will-increase.html>. Acesso em: 27 fev. 2015.

Figura 1 - Cópia da carta ao Ryokichi Sagane escrita pelo Luis Alvarez que foi jogada em Nagasaki.

\section{Energia nuclear}

A energia nuclear é a energia liberada em uma reação nuclear, especialmente fusão e fissão. O processo no qual dois núcleos leves se combinam para formar um núcleo mais pesado é chamado fusão nuclear, e aquele em que um núcleo pesado se rompe em dois outros núcleos menores é chamado fissão nuclear. Nesses processos ocorre a liberação de energia segundo a famosa equação de Einstein $E=m c^{2}$ que mostra a equivalência entre energia e massa, uma vez que em ambos os casos a massa total resultante é menor que a massa total inicial.

A fusão nuclear é a fonte de energia do sol e das estrelas. As bombas de hidrogênio, testadas a partir de 1951, são também um exemplo de liberação de energia pela fusão nuclear. Um reator de fusão é uma máquina capaz de controlar a produção de energia através da fusão de núcleos leves e os estudos para sua construção iniciaram em 1950. Mas devido à imensa complexidade, muita pesquisa precisa ainda ser feita antes da construção de um reator de potência comercial à base de fusão. Sua concretização provavelmente não ocorrerá antes de 2030 ou 2040. 
Os reatores nucleares de potência comerciais para a geração de energia elétrica do mundo funcionam à base de fissão. O combustível usado para aquecer a água do reator é feito de pastilhas contendo urânio-235 ou plutônio-239 que são elementos físseis, isto é, que sofrem fissão. Um núcleo pesado desses elementos, ao absorver um nêutron, pode se romper, formando dois ou mais núcleos leves, liberando energia cinética, radiação gama e dois ou três nêutrons. Alguns desses nêutrons podem em seguida atingir outros núcleos pesados, e iniciar assim uma reação em cadeia, como mostra a Figura 2. No caso de uma bomba atômica a reação em cadeia se desenvolve, enquanto em um reator nuclear ela é controlada.

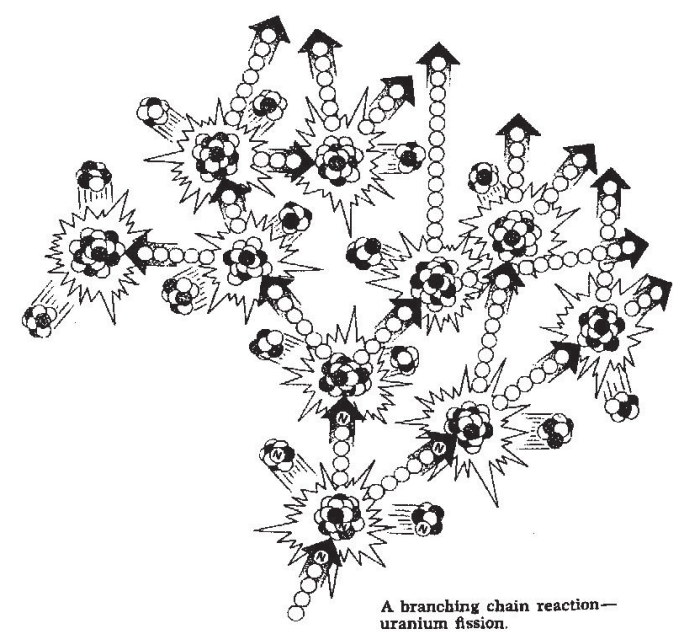

Fonte: Physics in Perspective. Eugene Hecht. Addison-Wesley (1980).

Figura 2 - Reação em cadeia deflagrada com um nêutron atingindo o núcleo de urânio-235.

\section{As bombas atômicas lançadas em Hiroshima e em Nagasaki}

Durante a Segunda Guerra Mundial foi desenvolvido nos Estados Unidos, em colaboração com a Grã-Bretanha e Canadá, um projeto para a construção de bombas atômicas que foi chamado Projeto Manhattan. De 1942 a 1946, o comando geral do projeto coube ao general Leslie Groves, que nomeou como diretor do projeto o físico Julius Robert Oppenheimer. Diversos laboratórios dos Estados Unidos participaram do projeto secretamente, destacando-se o de Oak Ridge, onde foi realizado o enriquecimento do urânio, o de Los Alamos, onde foram desenhadas e construídas as três bombas atômicas, o de Hanford, que produziu o plutônio, usado na bomba testada em Trinity, no Alamogordo e na bomba lançada em Nagasaki. A Figura 3 mostra foto da bomba Little Boy com o urânio-235 como elemento físsil e da réplica da bomba Fat Man tendo o plutônio-239 como elemento físsil.

Trabalharam no Projeto Manhattan cerca de 130 mil pessoas, sendo 21 Prêmios Nobel principalmente de Física, de vários países. 
As características e os efeitos das bombas lançadas em Hiroshima e Nagasaki estão listados na Tabela 1. A população de Hiroshima e Nagasaki por ocasião da explosão da bomba era de $(345 \pm 5)$ mil pessoas e $(260 \pm 10)$ mil pessoas, respectivamente.

As principais causas das mortes imediatas ou em curto espaço de tempo após a explosão das bombas em Hiroshima e Nagasaki foram:

1. Ondas de calor: de $20 \%$ a $30 \%$ das mortes de seres humanos num raio de $1,2 \mathrm{~km}$ do hipocentro são atribuídas a queimaduras fatais;

2. Ondas de choque: as pessoas que estavam na rua ou mesmo dentro de casa foram lançadas vários metros no ar, ferindo-as terrivelmente ou mesmo matando-as;

3. Radiação ionizante: raios gama e nêutrons emitidos durante a explosão além da radiação emitida por átomos de césio-137 e de iodo-131, por exemplo, que contaminaram pessoas interna e externamente. A chuva negra que começou a cair 20 min após explosão da bomba em Hiroshima e durou até 12 h45 contaminou uma área ovalada de $11 \mathrm{~km}$ por $19 \mathrm{~km}$.

Tabela 1 - Características e efeitos das bombas lançadas em Hiroshima e Nagasaki

\begin{tabular}{l|c|c}
\hline Características das bombas & Hiroshima (Little Boy) & Nagasaki (Fat Man) \\
\hline comprimento & $3,0 \mathrm{~m}$ & $3,2 \mathrm{~m}$ \\
\hline diâmetro & $0,7 \mathrm{~m}$ & $1,5 \mathrm{~m}$ \\
\hline massa & $4,4 \times 10^{3} \mathrm{~kg}$ & $4,5 \times 10^{3} \mathrm{~kg}$ \\
\hline elemento físsil & urânio-235 & $21 \times 10^{3} \mathrm{~kg}$ de TNT \\
\hline rendimento (equivalente a) & $16 \times 10^{3} \mathrm{~kg}$ de TNT & $503 \mathrm{~m}$ do solo \\
\hline altura de explosão & $600 \mathrm{~m}$ do solo & $35 \%$ \\
\hline destruição das construções & $92 \%$ & entre 60 mil e 80 mil pessoas \\
\hline $\begin{array}{l}\text { número de mortes até } \\
\text { dez/1945 }\end{array}$ & entre 90 mil e $166 \mathrm{mil}$ \\
\hline $\begin{array}{l}\text { pessoas } \\
\text { imediata }\end{array}$ & queimadura (60 \%) & queimadura (95\%) \\
\hline
\end{tabular}



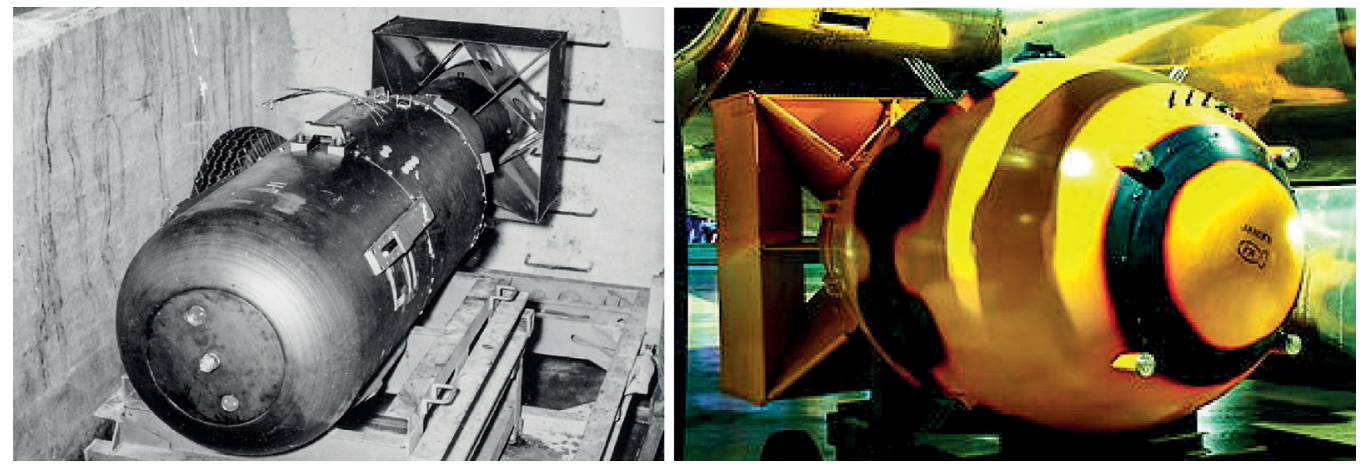

Fonte: Disponível em: <http://www.archives.gov/research_room/arc/>. <http:// en.wikipedia.org/wiki/Fat_Man\#mediaviewer/File:AirForceMuseum_FatManReplica. jpg>. Acesso em: 12 fev. 2015.

Figura 3 - A bomba Little Boy antes de ser montada no Enola Gay, à esquerda, e réplica da bomba Fat Man lançada em Nagasaki, à direita.

A cidade de Hiroshima antes a após a explosão da bomba atômica está ilustrada na Figura 4. Pode se observar a devastação total da cidade após a hecatombe nuclear.
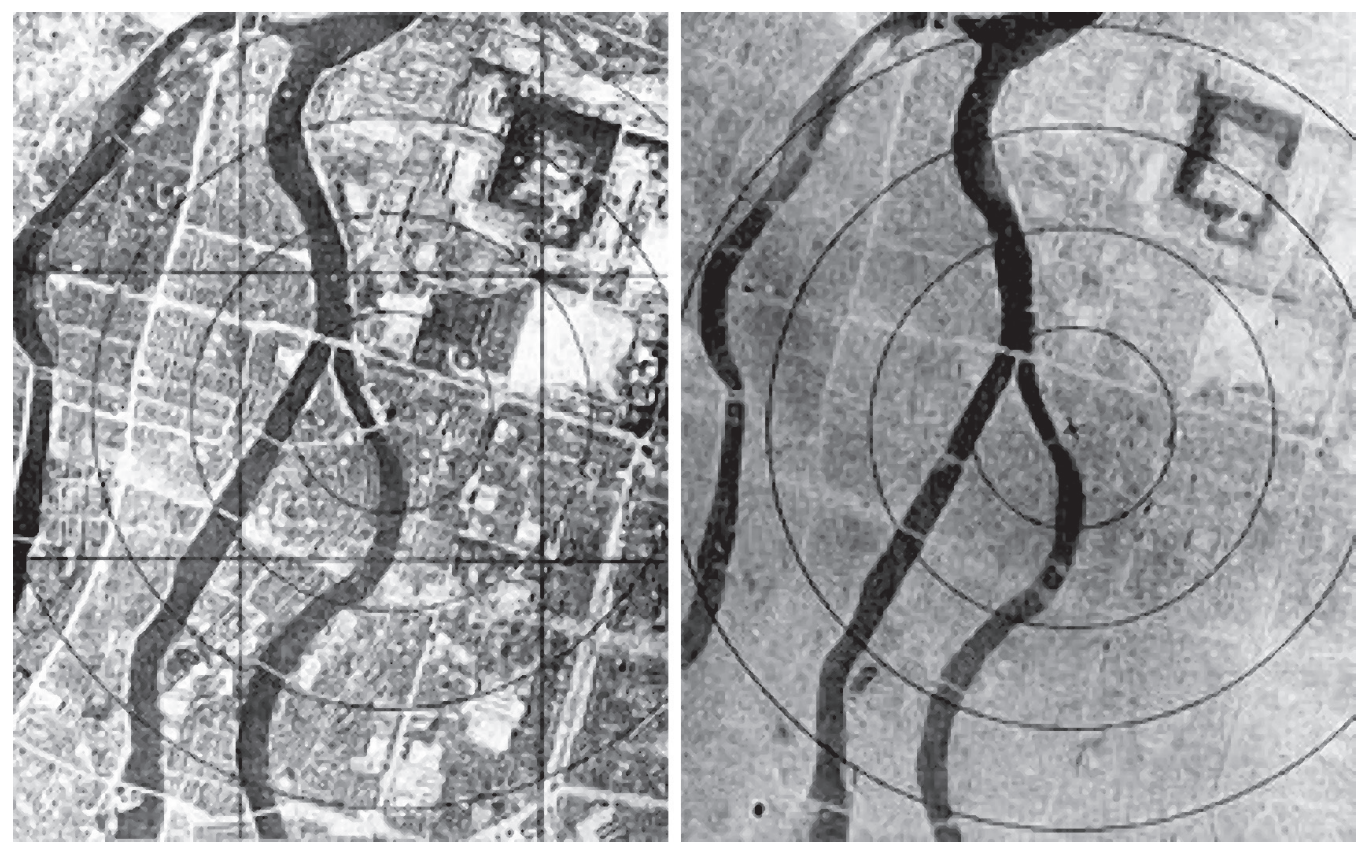

Fonte: Disponível em: <http://en.wikipedia.org/wiki/Atomic_bombings_of_Hiroshima_ and_Nagasaki\#mediaviewer/File:AtomicEffects-p7a.jpg>. Acesso em: 12 fev. 2015.

Figura 4 - Hiroshima antes do bombardeio, à esquerda, e após o bombardeio, à direita. 
A Figura 5 mostra, à esquerda, a foto dos danos causados pela bomba atômica em Hiroshima e do que restou de um dos poucos prédios, cuja torre é mantida como ficou, e à direita o torii, portal do xintoísmo, que ficou em pé em Nagasaki.

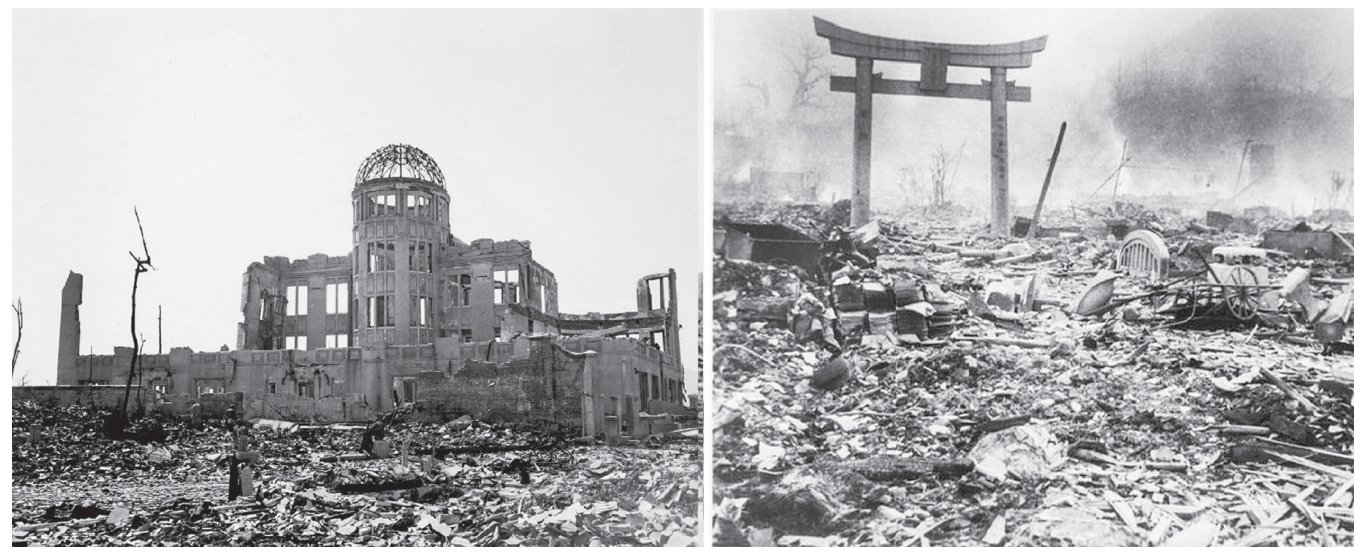

Fonte: Foto de Hiroshima: United States Strategic Bombing Survey e Foto de Nagasaki tirada por Yosuke Yamahata.

Figura 5 - Foto de um dos poucos prédios que restaram após o bombardeio em Hiroshima, à esquerda, e o torii que sobreviveu ao bombardeio em Nagasaki, à direita.

A nuvem de cogumelo que se formou logo após a explosão da bomba em Hiroshima pode ser vista na Figura 6, à esquerda, e em Nagasaki, à direita. Essas fotos foram tiradas de um dos B-29 que escoltaram os bombardeiros.

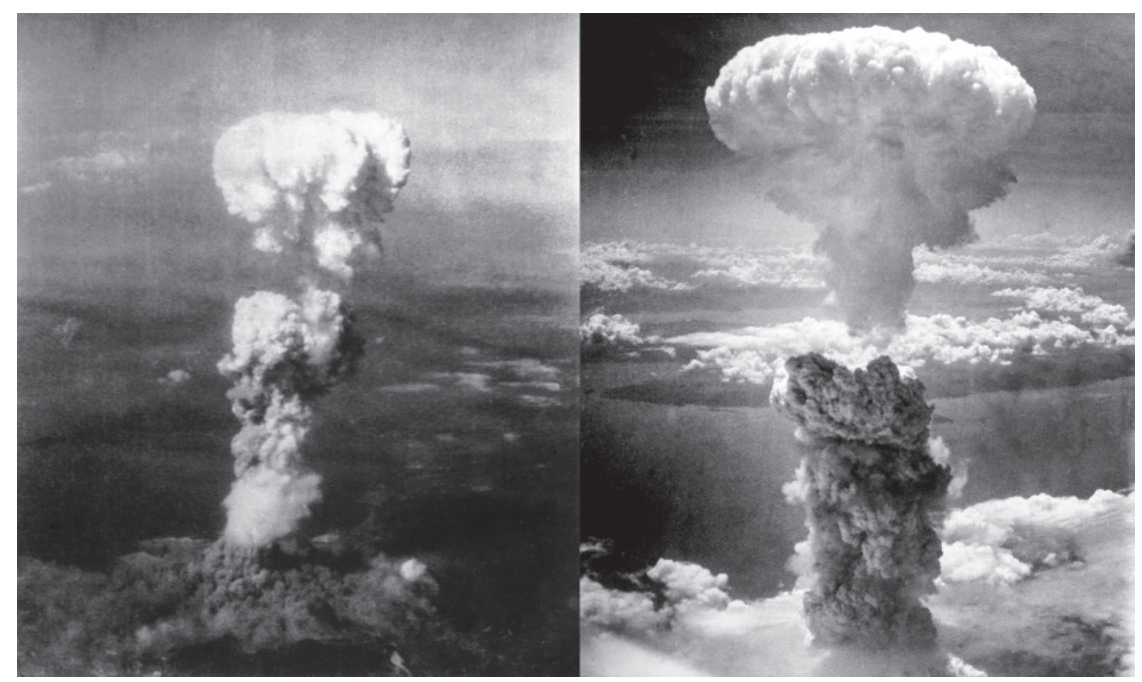

Fonte: Disponível em: <Nagasakibomb.jpg, Atomic_cloud_over_Hiroshima.jpg $>$. Acesso em: 18 fev. 2015.

Figura 6 - Nuvem em forma de cogumelo que se formou após a explosão das bombas em Hiroshima, à esquerda, e em Nagasaki, à direita. 
O presidente Harry S. Truman anunciou da Casa Branca em Washington que os americanos haviam explodido uma bomba atômica sobre a cidade de Hiroshima, passadas dezesseis horas. No dia 2 de setembro de 1945, foi assinada a ata de rendição do Japão em uma cerimônia oficial a bordo de encouraçado USS Missouri na Baía de Tóquio, terminando assim a Segunda Guerra Mundial.

\section{Efeitos da radiação ionizante à saúde humana}

A Atomic Bomb Casualty Commission (ABCC) foi estabelecida em Hiroshima em 1947 e em Nagasaki em 1948 sob os auspícios da U.S. National Academy of Sciences e do Japanese National Institute of Health, para iniciar os estudos epidemiológicos e genéticos dos efeitos tardios entre os sobreviventes das bombas atômicas. O objetivo principal dessa comissão foi acompanhar o estado de saúde de jovens expostos à radiação das bombas durante cem anos. Em 1975, ela foi sucedida pela Radiation Effects Research Foundation (RERF) que montou vários subprojetos. Entre eles, o Life Span Study (LSS) acompanha mais de 200 mil sobreviventes e seus filhos com foco na incidência e mortalidade de câncer. O LSS é o estudo epidemiológico mais importante do mundo relativo a efeitos tardios da radiação nos seres humanos devido ao seu tamanho, duração e informação fidedigna. Em um outro subprojeto, o Adult Health Study (AHS), os sobreviventes são examinados clinicamente por médicos duas vezes ao ano e realizados exames laboratoriais de sangue, urina, medidas de densidade óssea, disfunção cognitiva, verificação de incidência de catarata, de câncer de tireoide e útero. Além disso, são realizadas análises de frequência de aberrações cromossômicas em linfócitos.

Há também um subprojeto epidemiológico com indivíduos que eram fetos na época em que ocorreu a explosão da bomba.

Os dados coletados mostraram que a dose letal que mata $50 \%$ das pessoas expostas em um intervalo de 60 dias foi de 2,5 grays, quando não houve assistência médica, e 5 grays, com cuidados médicos. Lembramos que gray (Gy) é unidade de dose absorvida $D$ que é definida como energia $E$ da radiação depositada por unidade de massa $m$ ou seja $D=E / m$. Para fins de ilustração, informamos que segundo Unscear 2008 a taxa de dose absorvida média anual devida à radiação proveniente de fontes naturais é de 2,4 mGy.

\section{Efeitos agudos da radiação}

Esses efeitos ocorreram dentro de poucas horas a meses após receber uma dose alta de radiação desde 1 a 2 grays até 10 grays e apresentam o que foi chamada síndrome aguda da radiação. Os principais sinais e sintomas são: vômito dentro de poucas horas; seguido de diarreia com duração de dias a semanas; redução nas células sanguíneas; manifestações hemorrágicas; queda de pelos; inflamação na boca e garganta; febre e esterilidade masculina temporária. As mortes devidas à dose alta de radiação começaram cerca de uma semana após a exposição e alcançaram o máximo em três a quatro semanas, e cessaram praticamente após sete a oito semanas. 


\section{Efeitos tardios da radiação}

Efeitos tardios da radiação, tais como câncer e possivelmente outras doenças, ocorreram devido à mutação nos DNA; embora o mecanismo exato de como tais mutações levam ao câncer não seja conhecido, acredita-se que o processo requeira uma série de mutações acumuladas durante anos. Os resultados de dados coletados com sobreviventes mostraram que no caso de câncer sólido uma dose de 0,2 gray causa aumento na incidência de $10 \%$ em comparação com incidência dita "normal", para pessoas de igual idade. Para uma dose de 1 gray o correspondente excesso chega a atingir $50 \%$.

A probabilidade de um sobrevivente ter um câncer causado pela radiação da bomba depende de diversos fatores. $\mathrm{O}$ risco de ter câncer induzido pela radiação é tanto maior, quanto maior a dose recebida, quanto menor a idade do indivíduo quando é exposto à radiação, e ligeiramente maior nas mulheres em comparação aos homens.

O aumento na incidência de leucemia foi notado a partir de dois anos e atingiu o máximo de seis a oito anos após o bombardeio, principalmente em crianças, e depende fortemente da idade da exposição.

Outra informação obtida do projeto AHS é sobre aumento na incidência de tumores benignos de tireoide, de paratireoide, das glândulas salivares, uterinos e gástricos nas pessoas expostas à radiação da bomba atômica, com aumento de dose. As principais causas de morte são doenças cardiocirculatórias com incidência de aterosclerose também confirmada em mulheres que fizeram radioterapia de mama, seguido de doenças no sistema digestivo, no fígado e no sistema respiratório.

\section{Sadako Sasaki}

A menina-símbolo, vítima inocente de bomba atômica lançada em Hiroshima, é Sadako Sasaki (Figura 7), que tinha pouco mais de dois anos quando recebeu alta dose de radiação em Hiroshima e morreu de leucemia aos doze anos em outubro de 1955. Ela conseguiu fazer 644 origamis (dobraduras) de cegonha até a sua morte, inclusive com papel que continha remédio em forma de pó, que segundo uma lenda, seu desejo de se curar se realizaria ao dobrar um total de mil cegonhas. Suas colegas de escola arrecadaram fundos para a construção de um memorial para ela e todas as outras crianças que morreram vítimas de bomba atômica. Uma estátua de Sadako segurando uma cegonha (Figura 8) ficou pronta em 1958 e foi colocada no Parque da Hiroshima Peace Memorial, e ao seu pé há uma placa com as palavras: Este é nosso grito. Esta é nossa oração. Paz no mundo. 


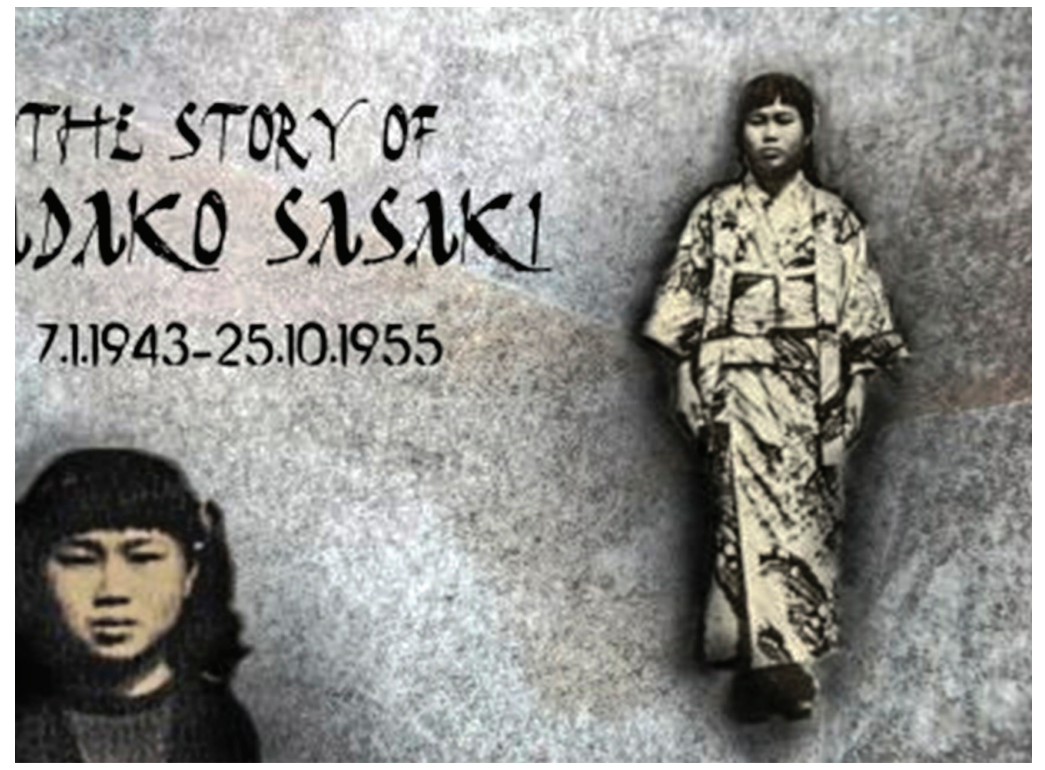

Fonte: Disponível em: <http://kraanvogelhoop.blogspot.com.br/2013/03/epiloog.html>.

Figura 7 - Sadako Sasaki, vítima inocente, numa foto tirada cerca de um ano antes de morrer de leucemia.

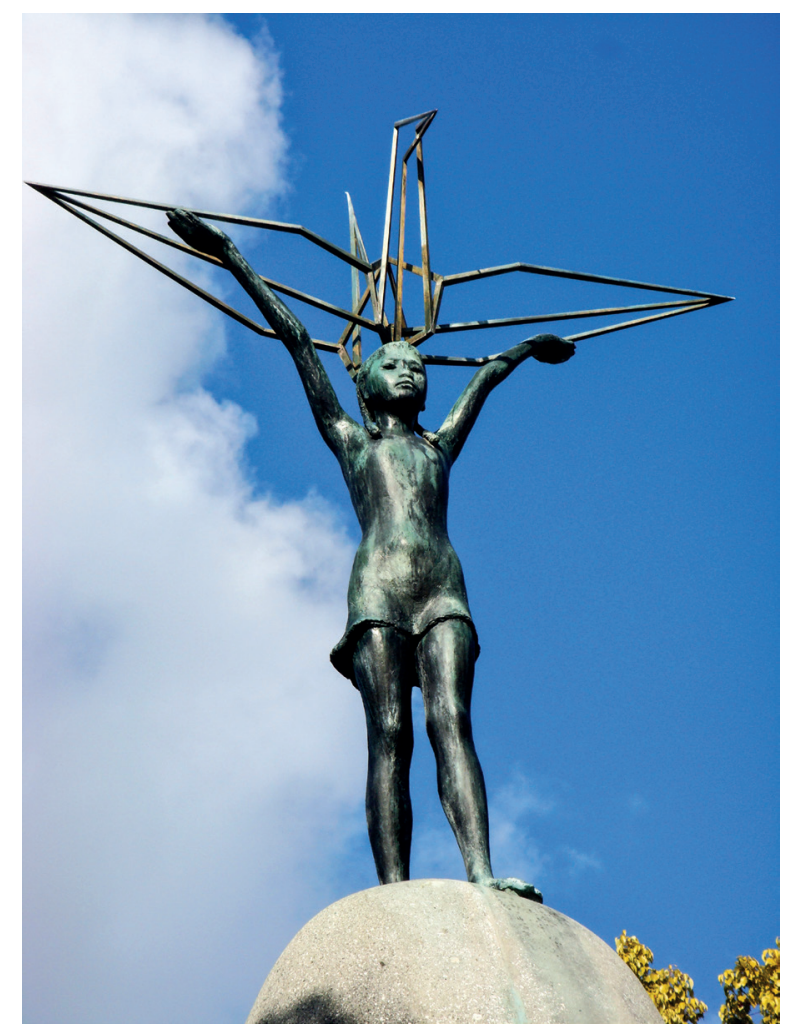

Fonte: Disponível em: <https://separatefictions.wordpress.com/tag/sadako-sasaki/>.

Figura 8 - Estátua da Sadako Sasaki, segurando uma dobradura de cegonha metálica no Parque da Hiroshima Peace Memorial. 
Referências

(RERF) RADIATION EFFECTS RESEARCH FOUNDATION. A Japan-US Cooperative Research Organization. A brief description (atualizado em 2012).

UNCEAR 2008. Sources and effects of ionizing radiation. Report to the General Assembly with scientific annexes. New York, v.1, 2010.

RESUMO - Este artigo rememora o que aconteceu há 70 anos após o lançamento pelos americanos das bombas atômicas Little Boy e Fat Man, respectivamente, nas cidades japonesas de Hiroshima e Nagasaki. Discorre suscintamente sobre energia nuclear e o Projeto Manhattan, que desenvolveu e produziu essas bombas e suas características. A destruição causada e os efeitos biológicos consequentes na população são também descritos.

PALAVRAS-CHAVE: Bombas atômicas, Little Boy, Fat Man, Hiroshima, Nagasaki.

ABSTRACT - This article recalls what happened 70 years ago after the dropping of the atomic bombs Little Boy and Fat Man in the Japanese cities of Hiroshima and Nagasaki respectively, by United States. Shortly describes about nuclear energy and the Manhattan Project, which developed and produced such weapons and their characteristics. The total destruction and the consequent biological effects in the population are also described.

KErWORDS: Atomic bombs, Little Boy, Fat Man, Hiroshima, Nagasaki.

Emico Okuno é professora sênior do Instituto de Física da Universidade de São Paulo. @ - emico.okuno@gmail.com

Recebido em 16.4.2015 e aceito em 5.5.2015.

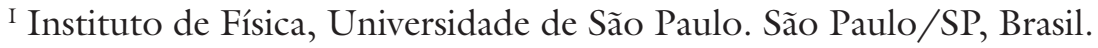

